\title{
Produksi Air Bersih di Ma'had Rizqullah Desa Simpang Sungai Duren Kecamatan Jambi Luar Kota Muara Jambi
}

\author{
Ahmad Riduan ${ }^{1}$, Rainiyati², Sarah Fiebrina Heraningsih², Dian Ariansyah² \\ 1,2 Universitas Jambi
}

\begin{tabular}{|c|c|}
\hline Article History & ABSTRACT \\
\hline $\begin{array}{l}\text { Received } 10.09 .2019 \\
\text { Received in revised form } \\
30.10 .2019 \\
\text { Accepted 03.12.2019 } \\
\text { Available online 16.12.2019 }\end{array}$ & $\begin{array}{l}\text { CLEAN WATER PRODUCTION IN RIZQULLAH ISLAMIC BOARDING } \\
\text { SCHOOL JAMBI. Pondok Pesantren is an Islamic boarding school where students } \\
\text { are learning about Islam as well as science and technologies. Adequate and good } \\
\text { quality of facilities and infrastructures are needed to support good teaching and } \\
\text { learning process. One of such facilities is clean and healthy water which is } \\
\text { important to students and teachers in the Pondok Pesantren. Bad quality of water, } \\
\text { either for washing or drinking, will affect students' concentration in studying. } \\
\text { Therefore, our community service project was aimed at improving the quality of } \\
\text { water at Ma'had Rizqullah by installing a clean water system using multilevel } \\
\text { filtration method. The water to be processed was ground water collected from } \\
\text { bore wells in Pondok area. By this technology, the requirement of clean water in } \\
\text { Ma'had Rizqullah can be met, al can also supply water needs for community } \\
\text { around the Pondok. The product of this technology was clean water that can be } \\
\text { used for daily activities by students and teachers living in Pondok and } \\
\text { surrounding people. }\end{array}$ \\
\hline & KEYWORDS: Clean Water, Filtration, Water Treatment. \\
\hline
\end{tabular}

DOI: $10.30653 / 002.201944 .225$

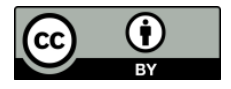

This is an open access article distributed under the terms of the Creative Commons Attribution 4.0 International License, which permits unrestricted use, distribution, and reproduction in any medium, provided the original work is properly cited. @ 2019 Ahmad Riduan, Rainiyati, Sarah Fiebrina Heraningsih, Dian Ariansyah.

\section{PENDAHULUAN}

Air merupakan senyawa yang sangat penting sebagai kebutuhan pokok bagi kehidupan manusia. Air sangat dibutuhkan dalam kehidupan sehari-hari manusia, terutama untuk minum dan memenuhi kebutuhan domestik seperti masak, mandi, mencuci dan sebagainya. Hampir $70 \%$ bagian dari bumi diselimuti oleh perairan baik berupa samudra, es, gletser, sungai maupun danau (Kundzewicz et al, 2007; Sutherland, 2012; Sutherland, 2014). Namun hanya kurang dari $1 \%$ air yang tersedia di bumi yang dapat langsung digunakan diantaranya berasal dari sungai, danau, sumur dan kolam. Pertumbuhan urbanisasi yang cepat, maju nya peradaban, pertumbuhan populasi, dan industrialisasi secara signifikan mencemari sumber daya alam baik secara langsung

\footnotetext{
${ }^{3}$ Corresponding author: Program Studi Teknik Kimia Universitas Jambi. Jl. Lintas Sumatera Jl. Jambi - Muara Bulian No.Km. 15, Mendalo
} Darat, Kec. Jambi Luar Kota, Kabupaten Muaro Jambi, Jambi 36122, Indonesia. Email: rye.zhu@ yahoo.com 
maupun tidak langsung dan menjadi ancaman bagi generasi mendatang. Hal ini menyebabkan masalah global yakni kelangkaan air bersih (Shannon et al, 2008). Pada saat ini, air bersih hanya menjangkau sebagian kecil persentase penduduk di Indonesia yang sebagian besar disuplai dari badan atau perusahaan air minum. Di daerah yang belum mendapatkan pelayanan air bersih tersebut, penduduk biasanya menggunakan air sumur galian, air sungai dan kanal yang kadang-kadang kurang memenuhi standar air bersih dan air minum yang sehat.

Pondok pesantren disamping berfungsi sebagai lembaga pendidikan Islam juga memiliki peran sebagai motor penggerak pembangunan dan perubahan dalam masyarakat. Aktivitas nyata pondok pesantren dalam memberdayakan kehidupan masyarakat dapat dilihat dari kemampuannya dalam kegiatan-kegiatan yang bertujuan menggali, merangsang dan meningkatkan social ekonomi masyarakat, pengembangan usaha produktif, serta mengupayakan kesempatan bagi masyarakat memperoleh kehidupan yang layak dengan pemanfaatan sumberdaya yang tersedia. Dua fungsi pesantren di atas selanjutnya melahirkan peluang kerjasama antara pondok pesantren dengan masyarakat yang bersifat simbiosis mutualisme. Tujuannya adalah untuk meningkatkan kualitas pendidikan agama masyarakat agar memiliki bekal pengetahuan agama islam yang lebih luas serta akhlak al-karimah. Dengan begitu generasi muda yang ditempa melalui lembaga pendidikan pesantren dapat diandalkan sebagai agen of change dalam proses pendidikan dan pemberdayaan masyarakat (Pramudito, 2017).

Untuk menciptakan suasana pembelajaran yang nyaman hal utama yang penting untuk diperhatikan ialah kebersihan. Dalam hal ini faktor penentu kebersihan adalah kualitas air yang digunakan dalam kehidupan sehari-hari. Air yang kotor akan memberikan efek samping yang kurang baik bagi kesehatan diantara nya bisa menyebabkan penyakit kulit. Ma'had Rizqullah merupakan salah satu pesantren tahfidz yang ada di jambi berlokasi di Simpang Sungai Duren. Saat ini air yang digunakan untuk kegiatan sehari-hari santri dan pengurus Ma'had ialah air dari sumur bor. Kondisi air yang digunakan keruh, berbau dan berminyak. Melihat kondisi tersebut maka diperlukan penerapan teknologi untuk memperbaiki kualitas air bersih di Ma'had Rizqullah.

Salah satu teknologi efektif yang banyak digunakan untuk menghasilkan air bersih ialah dengan cara filtrasi (Rassoulinejad-Mousavi, Azamat, Khataee, \& Zhang, 2019; Sutherland, 2012; Sutherland, 2014). Filtrasi adalah metode pemisahan fisik, yang digunakan untuk memisahkan antara cairan (larutan) dan padatan. Cairan yang telah melalui proses filtrasi/penyaringan disebut filtrat, sedangkan padatan yang tertumpuk di penyaring disebut residu (Prima, 2016). Teknologi filtrasi yang diaplikasikan pada masyarakat memiliki sistem backwash sehingga ketika pori-pori filter sudah jenuh residu bisa dibuang, tujuan dari sistem ini ialah untuk menjaga kualitas air minum. Pada kegiatan ini, teknologi pengolahan air sumur bor yang kotor menjadi air bersih kami gunakan adalah filtrasi bertingkat. 


\section{METODE PELAKSANAAN}

\section{Tempat dan Waktu Pelaksanaan}

Program pengabdian ini akan dilaksanakan di pondok pesantren Ma'had Rizqullah di desa Simpang Sungai Duren Kec. Jambi Luar Kota Muara Jambi. Pelaksanan pengabdian ini akan dilaksanakan mulai bulan Mei 2019 sampai dengan bulan Oktober 2019.

\section{Bahan dan Alat yang Digunakan}

Adapun bahan dan alat yang digunakan pada program pengabdian ini adalah Tedmond, Pipa, pompa, drum air, carbon, silika, mangan, kerikil, filter tank, dan tabung media.

\section{Pelaksanaan Kegiatan}

Kegiatan ini diawali dengan pertemuan antara tim pelaksana dengan pengurus dan santri dengan kegiatan awal penjelasan umum mengenai program pengabdian yang akan dilaksanakan Tim pengabdian dari Universitas Jambi. Selanjutnya dilakukan pemberian materi melalui kegiatan penyuluhan dan praktek pemasangan instalasi pengolahan air bersih. Kegiatan ini akan terus berlangsung sampai berakhirnya waktu kegiatan dengan pola pendampingan sampai menghasilkan produk air bersih yang dapat digunakan untuk kegiatan sehari-hari.

\section{Prosedur Kerja}

Prosedur kerja yang akan dilaksanakan meliputi penyuluhan dan penerapan Ipteks berupa pemasangan instalasi air bersih untuk masyarakat khususnya yang berlokasi di Ma'had Rizqullah. Proses Pemasangan dimulai desain awal diikuti dengan penyusunan peralatan serta pengisian media pada tabung yang dipersiapkan. Setelah proses pemasangan selesai, maka dilakukan backwash untuk membersihkan filter dan dilakukan uji coba hingga didapatkan air yang benar-benar bersih.

\section{HASIL DAN PEMBAHASAN}

\section{Survei Awal}

Kegiatan Survei Awal ini bertujuan untuk mengecek kondisi dilapangan. Hasil dari pengamatan di lapangan dilaporkan bahwa dalam kegiatan sehari-hari, mitra telah menggunakan air dari sumur bor yang ditampung dengan menggunakan dua buah tedmond. Air yang digunakan berwarna jernih namun masih memiliki bau dan rasa. 


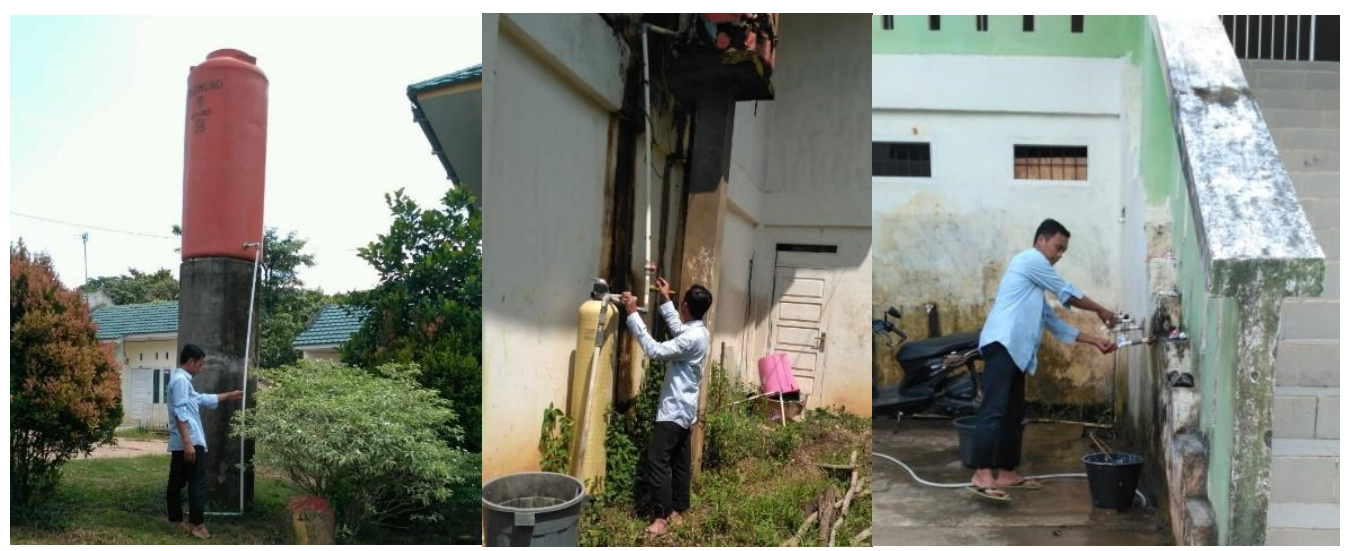

Gambar 1. Kegiatan Survei Awal

\section{Pembelian Alat dan Bahan}

Sebelum proses instalasi dilakukan identifikasi alat dan bahan yang diperlukan dalam kegiatan pengabdian. Alat dan bahan dipesan secara langsung ke toko yang menyediakan peralatan tersebut.

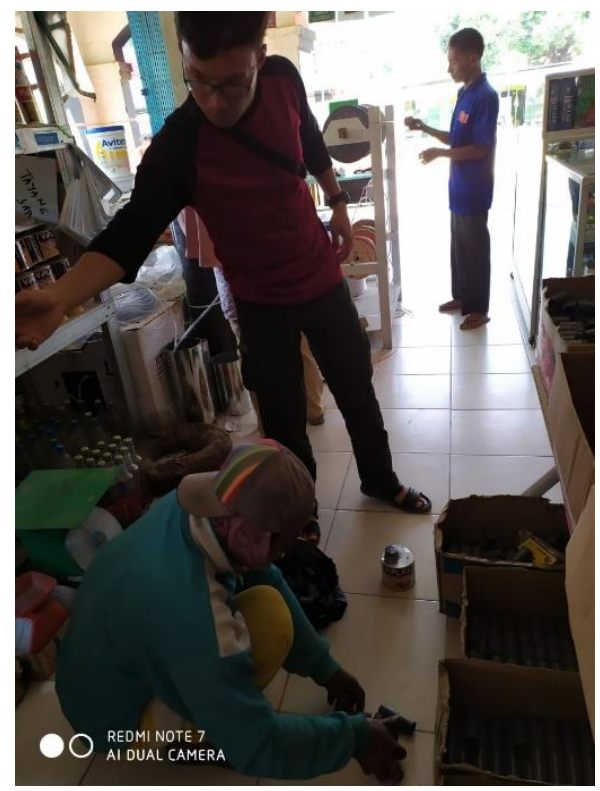

Gambar 2. Pembelian Peralatan

\section{Serah Terima Alat dan Bahan serta Pengarahan}

Proses serah terima bahan dan peralatan pengabdian dilakukan oleh seluruh anggota pengabdian bersama dengan pengurus Ma'had Rizqullah. Pada kegiatan ini ketua pengabdian juga memberikan saran masukan serta motivasi pada pengurus dan santri Ma'had Rizqullah. 


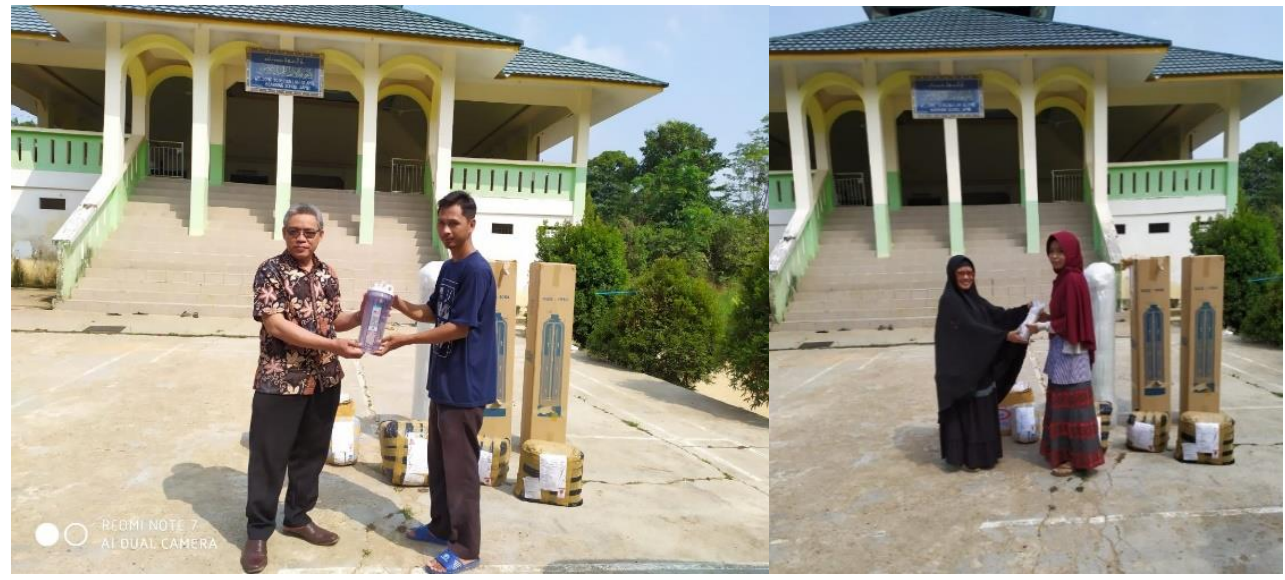

Gambar 3. Serah Terima Peralatan Pengabdian

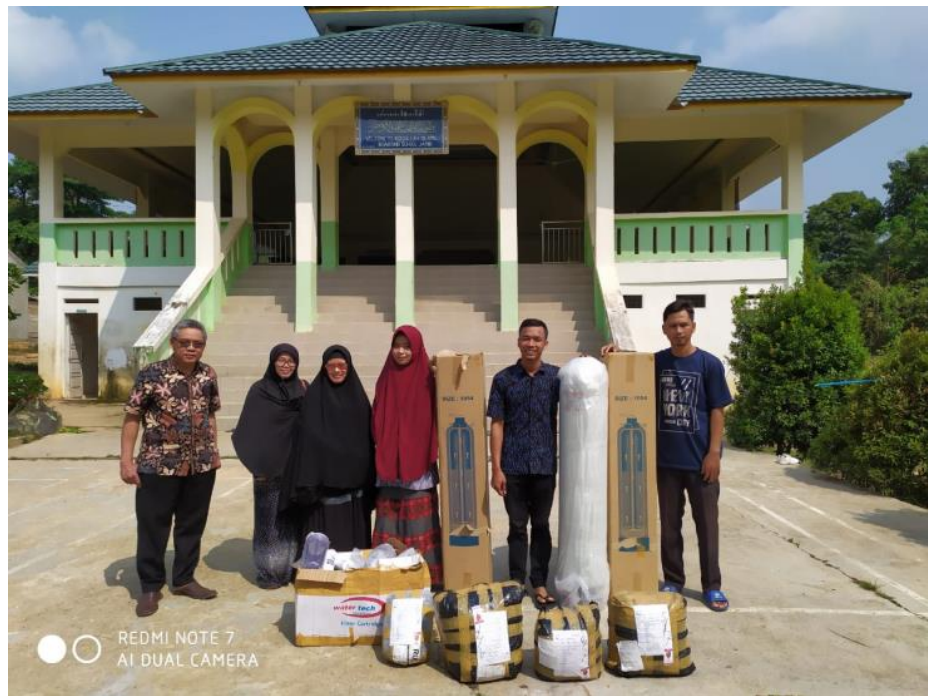

Gambar 4. Kegiatan Pengarahan kepada Pengurus Ma'had Rizqullah

\section{Desain Perangkat Air Besih}

Proses desain untuk instalasi air bersih dilakukan oleh koordinator lapangan dengan petugas instalasi untuk menggambarkan kesesuaian antara rancangan yang diinginkan dengan kondisi real di lapangan. 


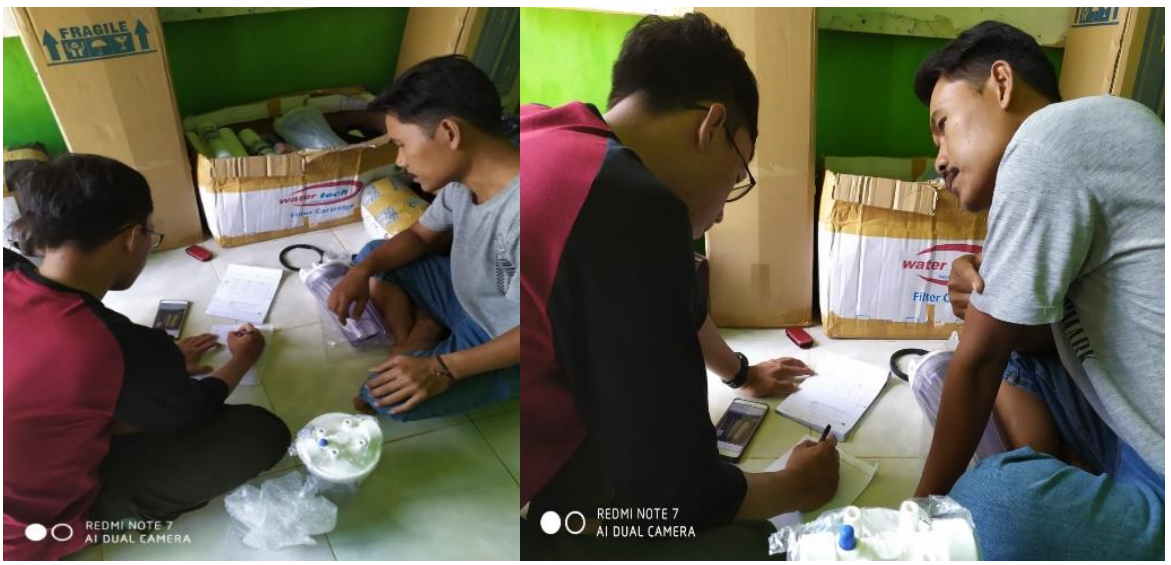

Gambar 5. Kegiatan Pendesainan Untuk Instalasi Pengolahan Air Bersih

\section{Instalasi}

Proses instalasi dilaksanakan dengan memasang 3 buah tabung media ukuran 1054 dengan pipa untuk aliran keluar masuk dan aliran backwashnya. Setelah itu dirangkai tabung media kecil yang berisi 9 buah filter media dan 1 buah carbon cto media. Tabung media diisi dengan urutan : tabung pertama berisi pasir silika, tabung kedua berisi zeolit karbon dan tabung ketiga berisi manganese untuk menghilangkan bau dan rasa.

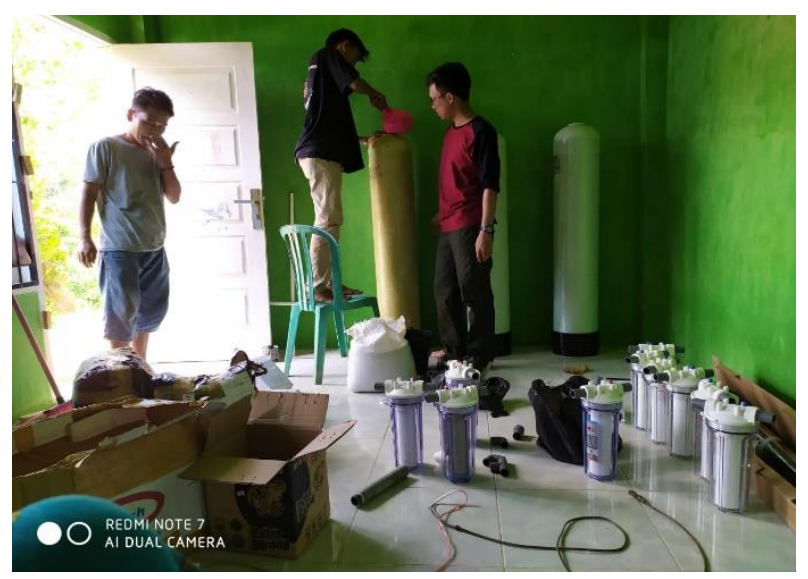

Gambar 6. Proses Pemasangan Instalasi Pengolahan Air Bersih Dan Pengisian Tabung Media

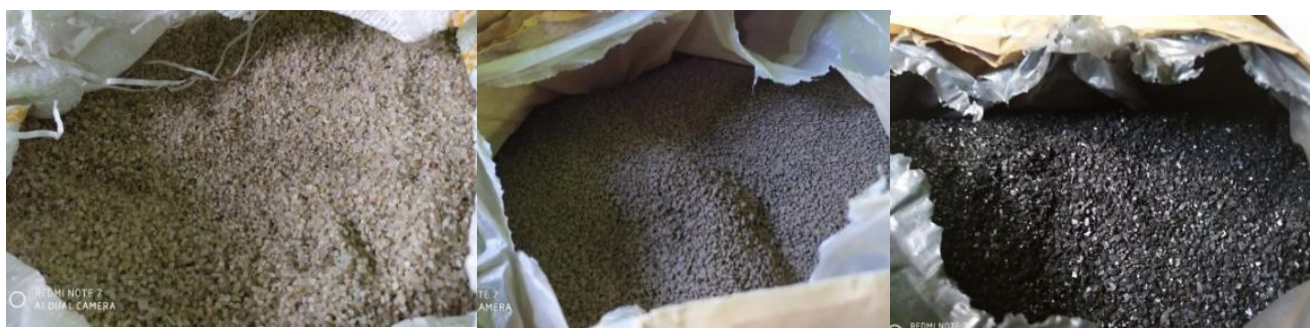

Gambar 7. Bahan Isian Tabung media : a) Pasir Silika ; b) Manganese; c) Zeolit Karbon

Setelah menyelesaikan seluruh proses perangkaian maka peralatan penyediaan air bersih diuji untuk melihat ada atau tidak nya kebocoran dan dilakukan backwash awal untuk membersihkan debu halus yang ada pada media. Dari uji awal menunjukkan bahwa laju aliran backwash pada media zeolit lebih lambat dibandingkan media silica 
dan manganese. Hal ini menunjukkan bahwa luas permukaan adsorpsi pada media zeolit lebih kecil, sehingga mampu memiliki daya adsorpsi maksimal.

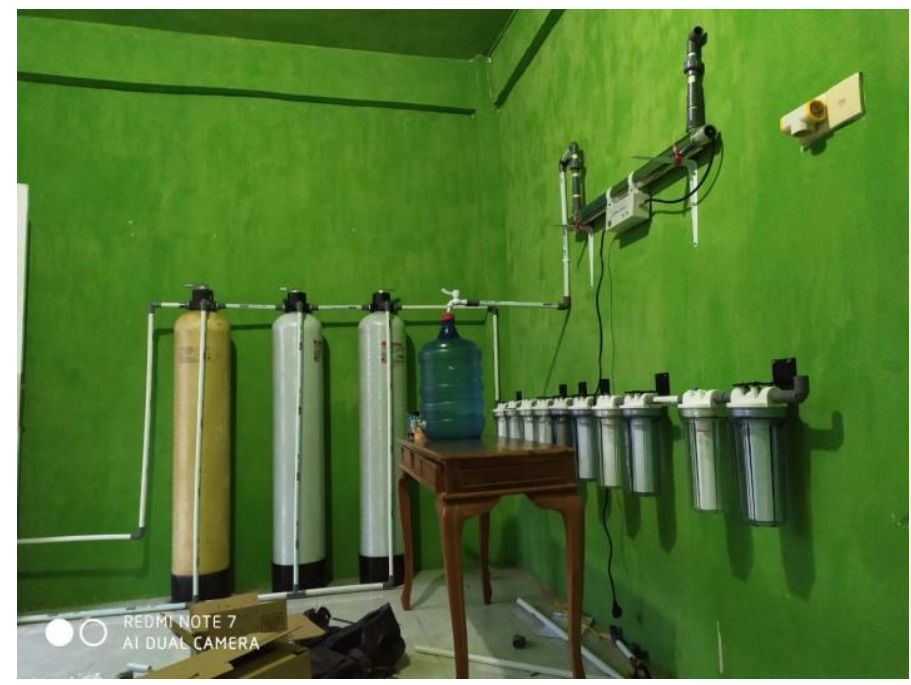

Gambar 8. Instalasi telah Terpasang

Setelah dilakukan serangkaian proses instalasi dan pengujian baik backwash maupun filtrasi, setelah 30 menit maka air yang dihasilkan ialah air bersih dan bening yang tidak berbau dan tidak berasa.

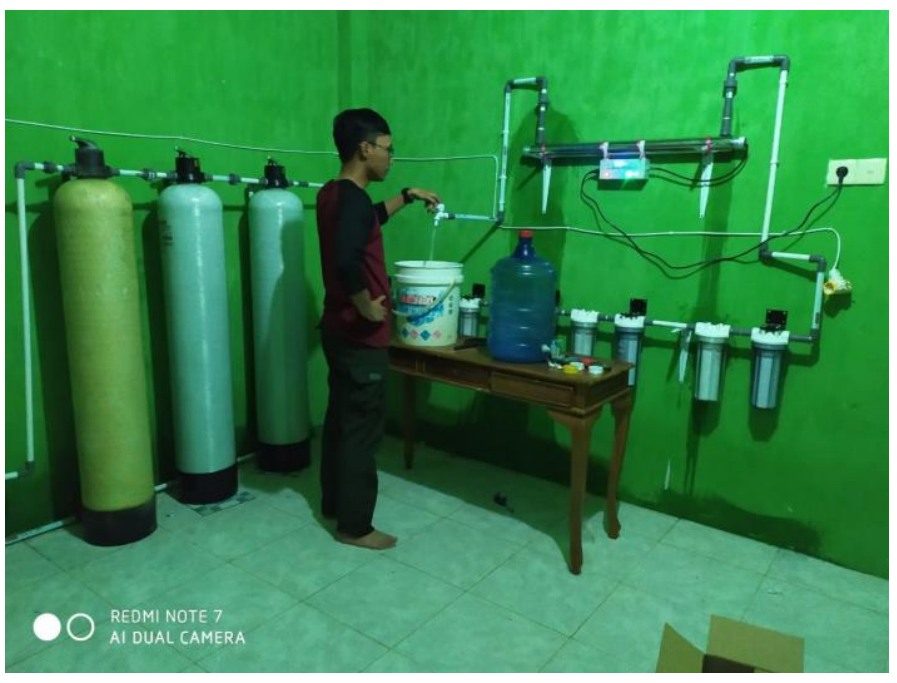

Gambar 9. Uji Coba Peralatan Pengolahan Air Bersih

\section{SIMPULAN}

Program Produksi Air Bersih yang dilaksanakan di Ma'had Rizqullah ini layak dilaksanakan karena dapat membantu pondok pesantren untuk dapat memiliki air yang sehat. Air yang bersih dapat meningkatkan kesehatan santri sehingga lebih konsentrasi dalam menuntut ilmu. 


\section{UCAPAN TERIMA KASIH}

Penelitian ini didanai oleh Lembaga Penelitian dan Pengabdian (LPPM) Universitas Jambi, dari dana PNBP LPPM Universitas Jambi.

\section{REFERENSI}

Kundzewicz, Z. W., Mata, L. J., Arnell, N. W., Döll, P., Kabat, B., Jimenez, B., ... Shiklomanov, I. A. (2007). Freshwater resources and their management. Climate Change 2007: Impacts, Adaptation and Vulnerability. In M. L. Parry, O. F. Canziani, J. P. Palutikof, P. J. van der Linden, \& C. E. Hanson (Eds.) Contribution of Working Group II to the Fourth Assessment Report of the Intergovernmental Panel on Climate Change, January 2007 (pp. 173-210). Cambridge: Cambridge University Press.

Pramudito. (2017). Bersama santri membangun ekonomi mandiri. Retrieved September 20, 2019, from http://harian.analisadaily.com/opini/news/bersama-santri-membangunekonomi-mandiri/306749/2017/01/26

Prima, R. D. (2016). Filtrasi. Retrieved September 20, 2019, from https://biologirendy.blogspot.com/2016/04/makalah-filtrasi.html

Rassoulinejad-Mousavi, S. M., Azamat, J., Khataee, A., \& Zhang, Y. (2019). Molecular dynamics simulation of water purification using zeolite MFI nanosheets. Separation and Purification Technology, 234, 1-8. https://doi.org/10.1016/j.seppur.2019.116080

Shannon, M. A., Bohn, P. W., Elimelech, M., Georgiadis, J. G., Marinas, B. J., \& Mayes, A. M. (2008). Science and technology for water purification in the coming decades. Nature, 452(20), 337-346. https://doi.org/10.1038/nature06599

Sutherland, K. (2012). Drinking and pure water: Filtration improvements progress global clean water provision. Filtration+ Separation, 49(2), 12-16. https://doi.org/10.1016/S0015-1882(12)70098-8

Sutherland, K. (2014). Drinking \& other pure water production: Filtration and sedimentation in clean water production. Filtration+ Separation, 51(1), 24-27. https://doi.org/10.1016/S0015-1882(14)70032-1 